\title{
Prospective and Retrospective Verbal Time Estimation in Children with ADHD
}

\author{
Marco Walg ${ }^{1}$ and Helmut Prior ${ }^{2}$ \\ 'Sana-Klinikum, Department for Child and Adolescent Psychiatry, Remscheid, Germany. \\ ${ }^{2}$ Goethe University, Institute of Psychology, Frankfurt am Main \& Rhine-Waal University of Applied Sciences, Faculty Society and \\ Economics, Kleve, Germany
}

ABSTRACT

There is increasing evidence that timing deficits represent a primary cause of key symptoms in ADHD. However, results in experiments on timing may vary with different methods of assessing timing competencies. The present study directly compared two central paradigms, namely, prospective and retrospective time estimation in children with $(n=30)$ and without $(n=29)$ ADHD. In both conditions, durations were estimated considerably longer by children with ADHD. Children with ADHD significantly overestimated the real duration of the task compared to children without ADHD in the retrospective but not in the prospective condition. In general, prospective estimates were more accurate than retrospective ones. The findings corroborate the essential role that timing deficits and a faster internal clock play in ADHD. Furthermore, the results demonstrate the importance of careful differentiation between prospective and retrospective time estimation.

\section{KEYWORDS}

ADHD

time processing

verbal time estimation

\section{INTRODUCTION}

Timing deficits may represent a primary cause of key symptoms in attention deficit hyperactivity disorder (ADHD; Walg et al., 2015), which is also of diagnostic relevance (Walg et al., 2017). Furthermore, a better understanding of timing deficits in children is important when it comes to supporting children with developmental dyscalculia (Tobia et al., 2018), which tends to show comorbidity with ADHD in a subset of cases (Morsanyi et al., 2018).

Attention deficit hyperactivity disorder is a neurodevelopmental disorder with multiple etiologies, in particular genetic, neurological, and environmental causes (Barkley, 2015). Generally, it is caused by the combined effects of numerous genetic and environmental factors, each of which have a small effect (cf. Faraone et al., 2021). Current models propose that an additive and interactive combination of multiple neuropsychological alterations causes specific clusters of deficits that are responsible for the clinical heterogeneity of ADHD (Willcut, 2015).
According to the triple pathway model (Sonuga-Barke et al., 2010), deficits in inhibitory control, delay-related processes, and deficits in temporal processing may account for the characteristics of different subtypes. Patients with ADHD show structural and functional deficits in brain regions that are crucially related to timing functions (Rubia, 2006). Although timing functions are intercorrelated with other executive functions, time-processing alterations appear to be an independent key deficit that is associated with the behavioral manifestations of ADHD, especially impulsiveness and inattention (Noreika et al., 2013). One explanatory model assumes that children with ADHD are en-

Corresponding author: Marco Walg, Zentrum für seelische Gesundheit des Kindes- und Jugendalters, Sana-Klinikum Remscheid, Weststraße 103, 42119, Wuppertal, Germany

Email:marco.walg@sana.de 
dowed with an internal clock that runs at a higher rate than in children with typical development (Rubia et al., 1999; Walg et al., 2015).

The sense of time is a complex concept that encompasses perceptual and cognitive processes which contribute to our experience of time and adjustments to specific environmental conditions (cf. Friedman, 2008). As such, psychological timing functions are commonly subcategorized into motor timing, perceptual timing, and temporal foresight (cf. Noreika et al., 2013). In the study of time perception, three techniques, namely the production method, the reproduction method, and the method of verbal estimation, are predominantly used. Due to the peculiarities of certain tasks, the different methods may lead to different result patterns (Grondin, 2008). Factors contributing to such differences are short versus long durations or intervals (Rammsayer, 1999), filled and unfilled intervals (Hicks et al., 1977), stimulus modality (cf. Plummer \& Humphrey, 2009), and the differentiation between two general paradigms of timing, that is, prospective and retrospective estimation (Block et al., 2018; Grondin, 2010).

In a prospective estimation task, subjects know that a duration judgment will be required prior to interval presentation. In a retrospective estimation task, subjects are asked for a judgment after duration presentation without prior warning (Hicks et al., 1976). According to the resource allocation model of time estimation (Zakay, 1989), most cognitive resources are allocated for temporal information during the interval in prospective estimation. However, more resources are allocated in retrospective estimation for nontemporal information, for example, for a concurrent task. Therefore, the prospective interval estimation is based on the temporal encoding of a stimulus duration. The basis for retrospective estimation is the nontemporal information processed during the interval and stored in memory. Therefore, retrospective estimation is also called "remembered duration," whereas the term "experienced duration" refers to prospective estimation (Block, 1990). Several studies have demonstrated that prospective judgments are generally longer, typically more accurate, and less variable than retrospective judgments (Block \& Zakay, 1997), but with tasks of increasing difficulty, prospective judgments shorten and retrospective ones lengthen (Block et al., 2010). A recent study has shown that the mean prospective estimates of routine daily activities that require a great deal of attention were longer than the retrospective estimates, but only $58 \%$ of the adult participants made longer prospective judgments than retrospective ones (Bisson \& Grondin, 2020). In children, prospective estimates of routine daily activities seem to be generally longer but less accurate than retrospective judgments (Bisson et al., 2012). Therefore, the distinction between remembered and experienced duration in verbal time estimation is crucial.

There is substantial evidence that timing functions and their underlying neural networks contribute to the symptoms of ADHD (Hart et al., 2012). Recent studies have strengthened the case for a genuine role of temporal processing (cf. Marx et al., 2017) and indicated that timing deficits persist into adulthood (Barkley \& Fischer, 2019; Pironti et al., 2016). For example, a study with thorough controls for an impulsivity bias indicated that children with ADHD have internal clocks that run faster than those of children without ADHD (Walg et al., 2015).
However, while both temporal processing in the range of seconds and temporal processing in the range of milliseconds were affected by ADHD, the specific pattern of changes was different in each of the two time windows (Walg et al., 2015).

In studies of temporal processing in $\mathrm{ADHD}$, the methods of duration discrimination, reproduction, and verbal time estimation were commonly used for examination (Block et al., 1999, provided descriptions of the methodology). In a meta-analysis of empirical studies published after the year 2000, minors with ADHD were found to show significant timing deficits, in particular a higher tendency for overestimating durations (Zheng et al., 2020). Timing deficits seem to be present in all subtypes of ADHD (Nejati \& Yazdani, 2020). According to a review by Toplak et al. (2006), most of the studies suggested timeprocessing alterations in ADHD in the form of higher discrimination thresholds or more discrepant reproductions (typically underestimations). Consistent with these findings, a recent study reported greater difficulties in discrimination between short and long time stimuli as well as under-reproduced time intervals in children with ADHD (Suarez et al., 2020). According to Carelli and Wiberg (2012), such impairments are found in studies with duration discrimination or duration reproduction but not in verbal time estimation. Indeed, no significant group differences have been found in the majority of studies with prospective verbal time estimation (Barkley, Edwards et al., 2001; Barkley, Murphy et al., 2001; Bauermeister et al., 2005; McGee et al., 2004; Meaux \& Chelonis 2003). By contrast, two other studies of prospective verbal time estimation (Hurks \& Hendriksen, 2011; Marx et al., 2017) found that children with ADHD made significant overestimations compared to controls.

In terms of retrospective verbal time estimation, Noreika et al. (2013) reported in a review that three studies found significantly higher overestimations in ADHD (Barkley, Murphy et al., 2001; Hurks \& Hendriksen, 2011; McGee et al., 2004) and four studies found no group differences (Barkley, Edwards et al., 2001; Bauermeister et al., 2005; Meaux \& Chelonis, 2003; Smith et al., 2002). However, four of these studies (Barkley, Murphy et al., 2001; Bauermeister et al., 2005; Meaux \& Chelonis, 2003) presented trials with different time intervals or had used practice intervals. The time estimations in these studies were therefore not retrospective, but prospective. A further study (Smith et al., 2002) showed no clear indication as to whether the instruction to estimate was given before or after duration presentation. Likewise, the study by Hurks and Hendriksen (2011) is not really comparable as time estimation was assessed by means of five questions (e.g., how long does it take for fresh milk to go sour in the refrigerator?) that do not require a judgment of the remembered duration of a sample time interval. Thus, only one of the studies reported (McGee et al., 2004) unequivocally used the method of retrospective verbal time estimation. In this study, children with ADHD overestimated a task duration compared to healthy controls. This result is in line with findings by Prevatt et al. (2011), who also found that children with ADHD overestimated a task duration compared to children without ADHD. In addition, participants in this study had to guess in advance how many minutes they would need to complete the task. Estimates of the ADHD group were 
significant longer than estimates of the non-ADHD group. Again, the results are not really comparable with regard to prospective verbal time estimation of an experienced duration as it did not require a judgment of a given time interval.

The aim of the present study was to clarify at least some of the inconsistencies in the present literature by directly comparing the sense of time in children with ADHD by means of prospective and retrospective verbal time estimation tasks. To our knowledge, this is the first study on prospective and retrospective time estimation with a comparable duration in children with ADHD. The comparison of these two methods with the same time interval, the same stimulus modality, and the same cognitive demands was intended to contribute to the systematic research of time perception in ADHD. We were interested in the accuracy as well as potential systematic bias for longer (or shorter) estimates. In keeping with the model of a faster internal clock in subjects with ADHD (Sonuga-Barke et al., 1998; Rubia et al., 1999) and based on our findings on nonverbal time estimation (Walg et al. 2015), we expected overestimations in participants with ADHD.

\section{METHODS}

\section{Participants}

The study involved a total of 74 children between the ages of 10 and 14 years. All subjects were patients in a children's rehabilitation hospital. They had a clinical diagnosis with ADHD or respiratory disease. Children with any diagnosed comorbid psychiatric disorder were excluded from the study. The psychosomatic inpatient treatment lasted from four to six weeks. The multidisciplinary treatment of ADHD included cognitive training, parent training, and social skills training. Children with respiratory disease were admitted to the hospital because of the very low air pollution in the area surrounding the hospital. Their treatment included walking therapy to breathe the saline air, nebulizer training, sport therapy, and relaxation training. After the diagnostic procedure (see below), 10 children who were supposed to have ADHD were excluded because their questionnaire scores were below the criteria for ADHD. Likewise, three children who were supposed to have no ADHD were excluded because their questionnaire scores met the criterion for ADHD. One child with respiratory disease was excluded because a comorbid depressive disorder had been diagnosed. One child in the ADHD group was excluded during checks for statistical outliers. Thus, after completing the diagnostic procedure, 30 children with ADHD combined subtype and 29 children without ADHD participated in the study. In the prospective condition, 24 boys and four girls took part, in the retrospective condition, there were 20 boys and 11 girls. Table 1 shows the main characteristics of the groups (ADHD vs. controls).

\section{Diagnostic Procedure}

Attention deficit hyperactivity disorder (combined subtype) was diagnosed by experienced pediatricians or psychiatrists prior to admission to the hospital according to European guidelines (Taylor et al., 2004). Subjects in the control group had respiratory diseases that have no known effects on overall cognitive functioning or time perception (cf.

\section{TABLE 1.}

Characteristics of the ADHD Group and Controls

\begin{tabular}{lcccc}
\hline & ADHD & Controls & Test for differences & \\
\hline & $M(S D)$ & $M(S D)$ & $t$ & $p$ \\
\hline Age (years) & $11.8(1.3)$ & $11.9(1.4)$ & 0.47 & .75 \\
IQ & $104(13)$ & $106(14)$ & 0.46 & .65 \\
Sex ratio & $25: 5$ & $19: 10$ & Fisher's exact test & .14 \\
$(n$ boys $: n$ girls $)$ & & & & \\
\hline
\end{tabular}

Kremer et al., 2002; Fryt et al., 2013). Psychiatric comorbidity was an exclusion criterion for either group. Prior to testing, the ADHD diagnosis and the absence of comorbidities were confirmed for each child. A structured clinical interview (EPSKI; Döpfner \& Petermann, 2012) assessed diagnostic criteria for psychiatric disorders in children according to the International Statistical Classification of Diseases and Related Health Problems, 10th Revision (ICD-10). Individuals with any indication of comorbidity, such as affective disorder, learning disorder, or conduct disorder, were excluded. In addition, all participants were evaluated with the German version of the Strengths and Difficulties Questionnaire (SDQ; Goodman 1997; filled in by children's parents) and a shortened form of Conners' Rating Scales (Steinhausen 2002; filled in by clinical staff). The SDQ consists of 25 items that assess hyperactivity/inattention, emotional symptoms, conduct problems, peer relationship problems, and prosocial behavior in children. The shortened form of Conners' Rating Scales contains 10 items that measure the typical symptoms of ADHD. Scores for children in the ADHD group had to be above the cutoff criteria for ADHD symptoms, whereas scores for the control group had to be below criteria. Scores for all children had to be below the cutoff values for emotional symptoms and conduct problems. Comprehensive behavioral observations by the clinical staff further confirmed the ADHD diagnosis. The children's IQs were assessed with the Culture Fair Intelligence Test (CFT 20-R; Weiß, 2006). Participants with IQs below 80 were excluded.

\section{Experimental Procedures}

Within a $2 \times 2$ design with group (ADHD vs. non-ADHD) and test condition (prospective vs. retrospective estimation) as factors, children in either group were randomly assigned to the test conditions. Time estimation was assessed two weeks after admission to the hospital. The assessment was conducted in an examination room for psychological testing in the hospital. No clocks were present in the room. Care was taken to ensure that participants had no watches or mobile phones with them. Each child was tested individually. The assessment was conducted by a psychologist who used a standardized instruction to explain the tasks at hand.

All subjects provided a verbal estimate on the duration of a simple discrimination task. During the discrimination task, short time intervals between 50 and $500 \mathrm{~ms}$ were visually presented on a computer screen, which had to be judged as either "long" or "short" by pressing a button. The entire discrimination task had an average duration of $424 \mathrm{~s}$. Due to the individual response times, the overall duration varied between the participants. The task duration did not differ between the two 
groups, $t(57)=1.1 ; p=.27$. Upon completing the discrimination task, the children were asked to estimate how long it had lasted (minutes and seconds), which was the verbal time estimation task.

In the retrospective condition, no prior indication that a judgment of the session duration would be required was provided. In the prospective condition, the children were informed about the required estimation of the duration of the discrimination task prior to testing. To ensure that the children in the prospective condition, particularly those diagnosed with ADHD, kept the verbal estimation task in mind, a preceding trial in this condition was provided: A shorter discrimination task was presented in advance and the children were asked to estimate the task's duration. In this manner, the requirement of a verbal duration judgment in the following test session was clarified, which made it a prospective estimation task. No information regarding the real task duration of the trial session was given to rule out any adjustment of estimations.

Before the beginning of the study, children and their parents had been informed in writing about the investigation and informed consent was obtained from all participants and their parents. All parts of the study were done in accordance with the rules of the Declaration of Helsinki.

\section{Measures}

The systematic error as well as the absolute error score were calculated from the variable estimates to measure performance. The systematic error is the signed (+/-) difference between estimated and individual real task duration. Therefore, this measure is sensitive to the direction of differences (over- and underestimates). The absolute error score represents the absolute value of the systematic error eliminating its signs, which reflects the magnitude of a participant's error in estimation regardless of the direction. The lower the absolute error score, the more accurate the estimation of the real task duration.

\section{Analysis}

After checking for outliers using Dixon's method, a $2 \times 2$ analysis of variance (ANOVA) with the factors of group (ADHD vs. control) and condition (prospective vs. retrospective) was used. The IQs of the groups were compared by means of $t$-tests. Any potential moderating effect caused by a gender was checked by an exploratory ANOVA with gender as a between-subjects factor.

\section{RESULTS}

\section{Verbal Time Estimation}

Table 2 provides an overview of all findings. As expected, there was a strong difference in absolute error scores between the prospective and retrospective conditions, $F(1,54)=11.35 ; p=.001 ; \eta^{2}=.17$. When the children were aware of the task beforehand, estimates were much more precise. There was no group $\times$ condition interaction, $F(1,54)=1.97 ; p=$ $.17 ; \eta^{2}=.04$, suggesting that children with ADHD and controls profited in a similar way; ADHD per se had no effect on accuracy, $F(1,54)=$ $0.58 ; p=.45 ; \eta^{2}=.01$. By contrast, there was no difference between the prospective and the retrospective condition in terms of systematic error.

Overall, prospective and retrospective conditions combined, children with ADHD made longer estimates than controls, $F(1,54)=5.65$; $p=.01$, one-tailed; $\eta^{2}=.09$. There was no group $\times$ condition interaction, $F(1,54)=0.73 ; p=.40 ; \eta^{2}=.01$, suggesting a consistent bias in ADHD for longer estimates.

In the prospective condition (see Figure 1), the task duration was underestimated by both groups. Children with ADHD gave longer estimates (on average, $24 \mathrm{~s}$ fewer than the true duration) than children without ADHD (on average, 89 seconds fewer than the true duration), but in this condition alone, there was only a trend, $F(1,28)=2.40 ; p=$ .08 , one-tailed; $\eta^{2}=.08$. There was no group effect for the accuracy of estimation, $F(1,28)=0.27 ; p=.61 ; \eta^{2}=.009$.

In the retrospective condition (see Figure 2), the difference between children with ADHD and controls was larger, $F(1,25)=3.21 ; p<.05-$ one tailed; $\eta^{2}=.11$. The mean task duration of $424 \mathrm{~s}$ was overestimated by an average of $66 \mathrm{~s}$ in the ADHD group, whereas it was underestimated by approximately $73 \mathrm{~s}$ in the control group. Again, there was no group effect for the absolute error score, $F(1,25)=1.81 ; p=.19 ; \eta^{2}=.07$.

\section{TABLE 2.}

Systematic Error and Absolute Error Scores in Prospective and Retrospective Verbal Time Estimation for All Subjects Combined and for Subjects With and Without ADHD in Total and in Each of the Two Conditions

\begin{tabular}{|c|c|c|c|c|c|c|c|c|}
\hline & \multicolumn{4}{|c|}{ Systematic error } & \multicolumn{4}{|c|}{ Absolute error score } \\
\hline & $M$ & $S D$ & ANOVA $F$ & Effect size $\eta^{2}$ & $M$ & $S D$ & ANOVA $F$ & Effect size $\eta^{2}$ \\
\hline Prospective estimates $(n=31)$ & -56 & 120 & \multirow{2}{*}{1.38} & \multirow{2}{*}{.02} & 105 & 79 & \multirow{2}{*}{$11.35^{\star *}$} & \multirow{2}{*}{.17} \\
\hline Retrospective estimates $(n=28)$ & -4 & 213 & & & 184 & 101 & & \\
\hline \multicolumn{9}{|l|}{ Both conditions } \\
\hline ADHD group $(n=30)$ & 18 & 184 & \multirow{2}{*}{$5.65^{*}$} & \multirow{2}{*}{.09} & 150 & 106 & \multirow{2}{*}{0.34} & \multirow{2}{*}{.006} \\
\hline Control group $(n=29)$ & -81 & 142 & & & 135 & 90 & & \\
\hline \multicolumn{9}{|l|}{ Prospective condition } \\
\hline ADHD group $(n=16)$ & -24 & 114 & \multirow{2}{*}{2.40} & \multirow{2}{*}{.08} & 98 & 58 & \multirow{2}{*}{0.27} & \multirow{2}{*}{.009} \\
\hline Control group $(n=15)$ & -89 & 121 & & & 113 & 98 & & \\
\hline \multicolumn{9}{|l|}{ Retrospective condition } \\
\hline ADHD group $(n=14)$ & +66 & 237 & \multirow{2}{*}{$3.21^{*}$} & \multirow{2}{*}{.11} & 209 & 118 & \multirow{2}{*}{1.81} & \multirow{2}{*}{.07} \\
\hline Control group $(n=14)$ & -73 & 166 & & & 159 & 78 & & \\
\hline
\end{tabular}

${ }^{*} p<.05 ;{ }^{* *} p<.01$ 

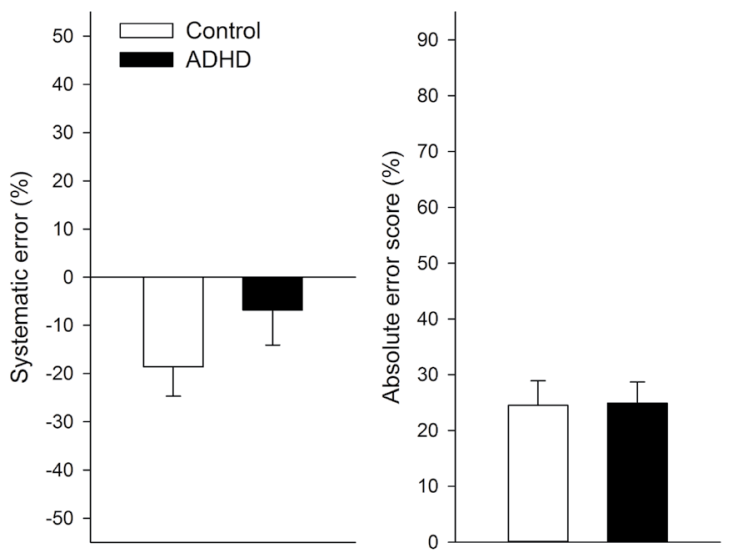

\section{FIGURE 1.}

Average deviations of prospective estimates in percent, means and SEM. Children with ADHD judged durations to be slightly longer than controls (systematic error, left panel). Accuracy (absolute error score, right panel) was remarkably similar in both groups.
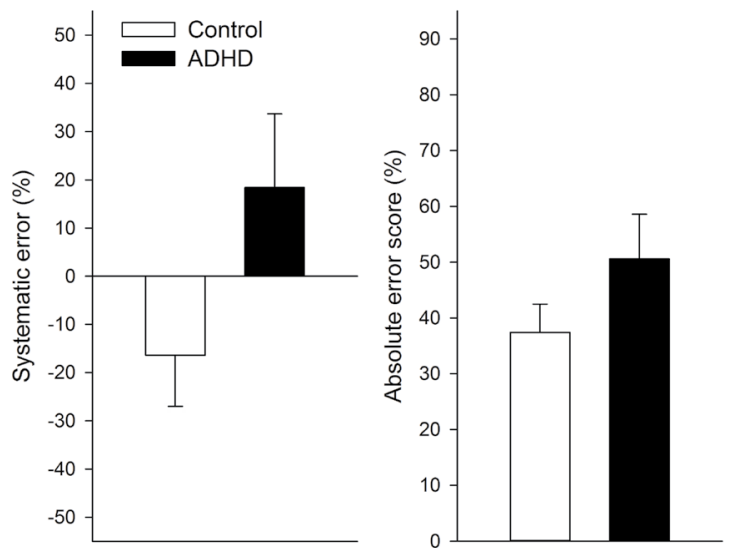

\section{FIGURE 2.}

Average deviations of retrospective estimates in percent, means and SEM. Children with ADHD judged durations to be longer than controls (systematic error, left panel). Compared with the true durations, children with $\mathrm{ADHD}$ were prone to overestimate, while controls tended to underestimate. Accuracy was somewhat better in children without $A D H D$, resulting in a higher absolute error score in the ADHD group; but there was no significant difference.

\section{Gender and IQ}

No significant gender differences were recorded in systematic errors, $F(1$, $57)=0.76 ; p=.39$, or in absolute error scores, $F(1,57)=2.98 ; p=.09$.

There was no significant divergence in IQ scores between the $\mathrm{ADHD}$ group (mean IQ $=104, S D=13$ ) and the control group (mean $\mathrm{IQ}=106, S D=14 ; t=.46 ; d f=57 ; p=.65)$. Also, there was no systematic effect of the covariate IQ on systematic errors, $F(1,56)=0.03 ; p=$ .87 , or absolute error scores, $F(1,56)=1.52 ; p=.22$.

\section{DISCUSSION}

Children with ADHD significantly overestimated the true duration of the task compared to children without ADHD in the retrospective, but not in the prospective condition. There was no significant group difference in the absolute error score in either condition. In general, prospective estimates were considerably more accurate than retrospective ones.

More accurate estimates in children who knew that duration judgments would be required subsequent to testing are consistent with earlier studies (Block \& Zakay, 1997). The higher level of accuracy may be due to cognitive preparations for the subsequent estimation while watching the interval in question. Such preparations may include the spontaneous use of counting strategies by children (Wilkening et al., 1987).

While the difference between children with ADHD and children without ADHD was not significant during prospective verbal time estimation, there was a fairly large significant difference for retrospective verbal time estimation. Children with ADHD overestimated the actual task duration by more than one minute on average, while children without $\mathrm{ADHD}$ underestimated it by more than one minute. The results underline the importance of careful differentiation between prospective and retrospective time perception.

The results suggest that different processes underlie prospective and retrospective time perceptions. Therefore, the findings on retrospective estimations should not be seen within the framework of the attentional model of prospective timing, but with regard to the contextual-change model of retrospective timing (Zakay \& Block, 2004). According to this model, remembered duration is based on the number of contextual changes encoded in memory during a given time interval. Increasing contextual changes and higher stimulus complexity lead to longer remembered duration.

Processing speed might be a relevant executive function that contributes to altered time perception in ADHD, in the prospective as well as in the retrospective time perceptions. According to the theory of Goddard (2000), slower processing speed in subjects with ADHD leads to a quick pace of events and situations. In the prospective paradigm, lower processing speed could underlie the relatively higher pacemaker speed in ADHD according to the attentional gate model. In the retrospective paradigm, lower processing speed may result in a quicker pace of events and situation. This would make concentration more difficult, cause distractibility and, therefore, lead to a subjectively higher rate of context changes resulting in longer remembered time durations. This assumption is supported by a study (Walg et al., 2017) that found lower processing speed indices rather than working memory to be related to less accurate retrospective duration estimates in subjects with ADHD. It is worth noting that theoretical models of ADHD have not proposed processing speed as a component that causes the key symptoms despite consistent findings of lower processing speed (cf. Willcut, 2015).

In everyday life, time estimation is crucial for predicting, anticipating, and responding efficiently to a variety of situations, for example, being on time for an appointment, calculating an appropriate time for doing homework or scheduling various other daily tasks. Findings of 
time-processing alterations in children with ADHD correspond with their parents' frequent reports that such children have a poor sense of time and time-related problems in daily activities (Quartier et al., 2010). Difficulties in retrospective time estimation in particular appear to be related to deficits in academic functioning in the college setting (Prevatt et al., 2011). Problems with temporal processing are still present in adults with ADHD (Valko et al., 2010). This may account for observed difficulties in professional life. Instruments for detecting timing deficits may enhance accuracy in ADHD diagnosis (cf. Bluschke et al., 2018; Gongsook et al., 2014). In this regard, the method of time estimation and the measure accuracy score appear to be particularly robust in terms of their high reliability (Marx et al., 2021). Earlier findings suggest that methylphenidate has a specific effect on improving timing deficits in ADHD (Smith et al., 2013). Recent studies have shown that cognitive training with time-related interventions, referred to as time-skills training, also improve everyday time management, facilitate the carrying out daily routines, and the occupational performance of children with ADHD (Wennberg et al., 2018; Wennberg et al., 2021). Timing skills are related to delay aversion and to impulsivity so that time-related trainings may reduce impulsive behaviors in children as well (Blume et al., 2019). Therefore, improving time perception should be given more consideration as a component in cognitive trainings for $\mathrm{ADHD}$, for example, by means of processing speed training or time estimation training. The latter may help to adjust the reference memory for timing according to the attentional gate model.

The findings emphasize the consideration of timing deficits in current models of ADHD as well as in the diagnostics and treatment of ADHD. Altered time perception should also be accounted for in parent training and in school settings (Ptacek et al., 2019). The faster internal clock in ADHD may result in reinforcing effects that wane more quickly (Sagvolden et al., 2005). Therefore, immediate reinforcement is an essential consequence for education. The consideration of these findings in classroom management may improve student behavior and, therefore, contribute to stress reduction for both students with ADHD and their teachers (cf. Lauth-Lebens \& Lauth, 2016).

The present study includes some limitations, in particular because of the sample. Earlier studies indicate that depression (Msetfi et al., 2012) or comorbid reading difficulties (Toplak et al., 2003) may impair time perception. There also seem to be differences in time perception between ADHD combined and ADHD inattentive subtypes (Mullins et al., 2005). For these reasons, any kind of comorbidity was excluded from the study. Consequently, the sample size was rather small. Another limitation were the respiratory diseases in the control group. In order to control the condition of the inpatient treatment, children with respiratory diseases were chosen to take part instead of healthy controls. To the best of our knowledge, children with respiratory diseases do not suffer from impairments in cognitive functioning that might affect time perceptions of the tested duration (cf. Fryt et al., 2013; Kremer et al., 2002). Although it is unlikely that respiratory diseases impair the perception of a time interval of several minutes in duration, the influence of these diseases cannot be entirely excluded. A further limitation is that only one time interval was investigated. This was due to the method of retrospective time estimation, which allows for only one trial, since no prior indication that a duration judgment would be required can be provided. In light of this, more research with larger sample sizes and healthy controls is still necessary.

\section{CONCLUSION}

Our findings further support the presence of a faster internal clock in children with ADHD. Furthermore, they demonstrate the importance of differentiating carefully between prospective and retrospective time estimation, as well as between the systematic error and the absolute error score. While children with ADHD profited, as did the control subjects, from having prior knowledge of the task in terms of accuracy, the systematic error revealed their specific pattern of altered temporal processing. Processing speed may underlie time perception alterations that cause typical symptoms of ADHD. Therefore, theoretical models of ADHD must account for processing speed deficits and time perception alterations and clarify their relationships within a multiple-deficits model to contribute to a better understanding of the etiology of ADHD.

\section{REFERENCES}

Barkley, R. A. (2015). Etiologies of ADHD. In R. A. Barkley (Ed.), Attention-deficit hyperactivity disorder: A handbook for diagnosis and treatment, fourth edition (pp. 356-390). The Guilford Press.

Barkley, R. A., Edwards, G., Laneri, M., Fletcher, K. \& Metevia, L. (2001). Executive functioning, temporal discounting, and sense of time in adolescents with attention deficit hyperactivity disorder (ADHD) and oppositional defiant disorder (ODD). Journal of Abnormal Child Psychology, 29, 541-556. doi: 10.1023/A:1012233310098 المالسلس

Barkley, R. A. \& Fischer, M. (2019). Time reproduction deficits at young adult follow-up in childhood ADHD: The role of persistence of disorder and executive functioning. Developmental Neuropsychology, 44, 50-70. doi: 10.1080/87565641.2018.1541992 الفلسلسلس

Barkley, R. A., Murphy, K. R. \& Bush, T. (2001). Time perception and reproduction in young adults with attention deficit hyperactivity disorder. Neuropsychology, 15, 351-360. doi: 10.1037/0894-

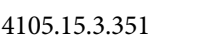

Bauermeister, J. J., Barkley, R. A., Martínez, J. V., Cumba, E., Ramírez, R. R., Reina, G., Matos, M. \& Salas, C.C. (2005). Time estimation and performance on reproduction tasks in subtypes of children with attention deficit hyperactivity disorder. Journal of Clinical Child and Adolescent Psychology, 34, 151-162. doi: 10.1207/s15374424jccp3401_14 المالسلس

Bisson, N. \& Grondin, S. (2020). A new perspective on the relationship between individual factors and time estimates. Timing \& Time Perception, 8, 25-54. doi: 10.1163/22134468-20191160 سلسلس

Bisson, N., Tobin, S. \& Grondin, S. (2012). Prospective and retrospective time estimates of children: A comparison based on ecological tasks. PLoS One 7, e33049. doi: 10.1371/journal.pone.0033049 السلسلس

Block, R. A. (1990). Models of psychological time. In R. A. Block (Ed.), Cognitive models of psychological time (pp. 1-35). Erlbaum.

Block, R. A., Grondin, S. \& Zakay, D. (2018). Prospective and retro- 
spective timing processes: Theories, methods, and findings. In A. Vatakis, F. Balci, M. Di Luca, \& A. Correa (Eds), Timing and time perception: procedures, measures, and applications (pp. 32-51). Brill.

Block, R. A., Hancock, P. A. \& Zakay, D. (2010). How cognitive load affects duration judgments: A meta-analytic review. Acta Psychologica, 134, 330-343. doi: 10.1016/j.actpsy.2010.03.006

Block, R. A. \& Zakay, D. (1997). Prospective and retrospective duration judgments: A meta-analytic review. Psychonomic Bulletin \& Review 4, 184-197. doi: 10.3758/BF03209393 سلس السلس

Block, R. A., Zakay, D. \& Hancock, P. A. (1999). Developmental changes in human duration judgments: A meta-analytic review. Developmental Review, 19, 183-211. doi: 10.1006/drev.1998.0475

Blume, F., Kuehnhausen, J., Reinelt, T., Wirth, A., Rauch, W. A., Schwenck, C. \& Gawrilow, C. (2019). The interplay of delay aversion, timing skills, and impulsivity in children experiencing attention-deficit/ hyperactivity disorder (ADHD) symptoms. ADHD Attention Deficit and Hyperactivity Disorders, 11, 383-393. doi: 10.1007/s12402-019-00298-4 سلس

Bluschke, A., Schuster, J., Roessner, V. \& Beste, C. (2018). Neurophysiological mechanisms of interval timing dissociate inattentive and combined ADHD subtypes. Scientific Reports, 8, 2033. doi: 10.1038/s41598-018-20484-0 0

Carelli, M. G. \& Wiberg, B. (2012). Time out of mind: temporal perspective in adults with ADHD. Journal of Attention Disorders, 16, 460-466. doi: 10.1177/1087054711398861 سلس لس

Döpfner, M. \& Petermann, F. (2012). Diagnostik psychischer Störungen im Kindes- und Jugendalter [Diagnostics of psychiatric disorders in children and adolescents]. Hogrefe.

Faraone, S. V., Banaschewski, T., Coghill, D., Zheng, Y., Biedermann, J, Bellgrove, M. A. et al. (2021). The world federation of ADHD international consensus statement: 208 evidence-based conclusions about the disorder. Neuroscience and Biobehavioral Reviews, 128, 789-818. doi: 10.1016/j.neubiorev.2021.01.022 السلسلس

Friedman, W. J. (2008). Developmental perspectives on the psychology of time. In: S. Grondin (Ed.), Psychology of time (pp. 345-366). Emerald

Fryt, J., Pilecka, W. \& Smolen, T. (2013). Does asthma disturb executive functions and self-regulation in children? Polish Journal of Applied Psychology, 12, 55-74. 郋

Goddard, J. (2000). Perceived passage of time: its possible relationship to attention-deficit hyperactivity disorder. Medical Hypotheses, 55, 351-352. doi: 10.1054/mehy.2000.1067 1لس

Gongsook, P., Peijnenborgh, J., Sallustro, C., van der Spek, E., Bellotti, F., Rauterberg, M. \& Hendriksen, J. (2014). A diagnostic tool on time perception of children with ADHD. In: A. De Gloria (Ed.), Games and learning alliance, vol 8605. Lecture notes in computer science (pp. 400-405). Springer.

Goodman, R. (1997). The strengths and difficulties questionnaire: A research note. Journal of Child Psychology and Psychiatry, 38,

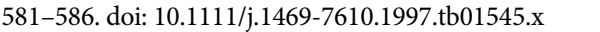

Grondin, S. (2008). Methods for studying psychological time. In: S. Grondin (Ed.), Psychology of time (pp. 51-74). Emerald.
Grondin, S. (2010). Timing and time perception: A review of recent behavioral and neuroscience findings and theoretical directions. Attention, Perception \& Psychophysics, 72, 561-582. doi: 10.3758/ APP.72.3.561 سلس

Hart, H., Radua, J., Mataix-Cols, D. \& Rubia, K. (2012). Meta-analysis of fMRI studies of timing in attention-deficit hyperactivity disorder (ADHD). Neuroscience \& Biobehavioral Reviews, 36, 2248-2256. doi: 10.1016/j.neubiorev.2012.08.003 الم

Hicks, R. E., Miller, G. W., Gaes, G. \& Bierman, K. (1977). Concurrent processing demands and the experience of time-in-passing. American

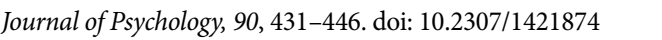

Hicks, R. E., Miller, G. W. \& Kinsbourne, M. (1976). Prospective and retrospective judgments of time as a function of amount of information processed. American Journal of Psychology, 89, 719-730. doi: 10.2307/1421469 سلس

Hurks, P. \& Hendriksen, J. (2011). Retrospective and prospective time deficits in childhood ADHD: The effects of task modality, duration, and symptom dimensions. Child Neuropsychology, 17, 34-50. doi: 10.1080/09297049.2010.514403 سلس

Kremer, B., Den Hartog, H. M. \& Jolles, J. (2002). Relationship between allergic rhinitis, disturbed cognitive functions and psychological well-being. Clinical \& Experimental Allergy, 32, 1310-1315. doi:

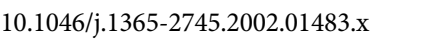

Lauth-Lebens, M. \& Lauth, G. W. (2016). Behavioral modification and classroom management skills as protective factors against mental health problems in teachers: A synthesis of research. Journal of Mental Disorders and Treatment, 2, 107.

Marx, I., Rubia, K., Reis, O. \& Noreika, V. (2021). A short note on the reliability of perceptual timing tasks as commonly used in research on developmental disorders. European Child \& Adolescent

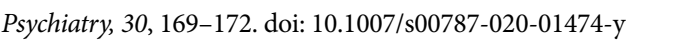

Marx, I., Weirich, S., Berger, C., Herpertz, S. C., Cohrs, S., Wandschneider, R., Höppner, J. \& Häßler, F. (2017). Living in the fast lane: evidence for a global perceptual timing deficit in childhood ADHD caused by distinct but partially overlapping task-dependent cognitive mechanisms. Frontiers in Human Neuroscience, 11:122 doi.org/10.3389/fnhum.2017.00122.

McGee, R., Brodeur, D., Symons, D., Andrade, B. \& Fahie, C. (2004). Time perception: Does it distinguish ADHD and RD children in a clinical sample? Journal of Abnormal Child Psychology, 32, 481-490. doi: 10.1023/B:JACP.0000037778.61929.1b لسلس

Meaux, J. B. \& Chelonis, J. J. (2003). Time perception differences in children with and without ADHD. Journal of Pediatric Health Care, 17, 64-71. doi: 10.1067/mph.2003.26 سلس

Morsanyi, K., van Bers, B. M. C. W., McCormack, T. \& McGourty, J. (2018). The prevalence of specific learning disorder in mathematics and comorbidity with other developmental disorders in primary school-age children. British Journal of Psychology, 109, 917-940. doi: 10.1111/bjop.12322 السلسلسلس

Plummer, C. \& Humprey, N. (2009). Time perception in children with ADHD: The effects of task modality and duration. Child Neuropsychology, 15, 147-162. doi: 10.1080/09297040802403690 المالسلسل 
Msetfi, R. M., Murphy, R. A. \& Kornbrot, D. E. (2012). The effect of mild depression on time discrimination. The Quarterly Journal of Experimental Psychology, 65, 632-645. doi:

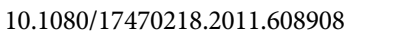

Mullins, C., Bellgrove, M. A., Gill, M. \& Robertson, I. H. (2005). Variability in time reproduction: Difference in ADHD combined and inattentive subtypes. Journal of the American Academy of Child \& Adolescent Psychiatry, 169-176. doi: 10.1097/00004583200502000-00009 السلسلس

Nejati, V. \& Yazdani, S. (2020). Time perception in children with attention deficit-hyperactivity disorder (ADHD): Does task matter? A meta-analysis study. Child Neuropsychology, 26, 900-916. doi:

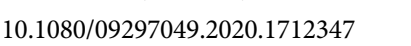

Noreika, V., Falter, C. M. \& Rubia, K. (2013). Timing deficits in attention-deficit/hyperactivity disorder (ADHD): Evidence from neurocognitive and neuroimaging studies. Neuropsychologia, 51, 235-266. doi: 10.1016/j.neuropsychologia.2012.09.036 المسلسلسل

Pironti, V. A., Lai, M.-C., Morein-Zamir, S., Müller, U., Bullmore, E. T. \& Sahakian, B. J. (2016). Temporal reproduction and its neuroanatomical correlates in adults with attention deficit hyperactivity disorder and their unaffected first-degree relatives. Psychological Medicine, 46, 2561-2569. doi: 10.1017/S003329171600101X السلسلس

Prevatt, F., Proctor, B., Baker, L., Garrett, L. \& Yelland, S. (2011). Time estimation abilities of college students with ADHD. Journal of Attention Disorders, 15, 531-538. doi: 10.1177/1087054710370673 اله

Ptacek, R., Weissenberger, S., Braaten, E., Klicperova-Baker, M., Goetz, M., Raboch, J., Vnukova, M. \& Stefano, G.B. (2019). Clinical implications of the perception of time in attention deficit hyperactivity disorder (ADHD): A review. Medical Science Monitor: International Medical Journal of Experimental and Clinical Research, 25, 39183924. doi: 10.12659/MSM.914225 المالسلس

Quartier, V., Zimmermann, G. \& Nashat, S. (2010). Sense of time in children with attention-deficit/ hyperactivity disorder (ADHD): A comparative study. Swiss Journal of Psychology/Schweizerische Zeitschrift für Psychologie/Revue Suisse de Psychologie, 69, 7-14. doi: 10.1024/1421-0185/a000002 المالسلس

Rammsayer, T. (1999). Neuropharmacological evidence for different timing mechanisms in humans. Quarterly Journal of Experimental Psychology B, Comparative and Physiological Psychology, 52, 273286. المالسلس

Rubia, K. (2006). The neural correlates of timing functions. In J. Glicksohn, \& M. S. Myslobodsky (Eds.), Timing the future: The case for a time-based prospective memory (pp. 213-238). World Scientific Publishing.

Rubia, K., Taylor, A., Taylor, E. \& Sergeant, J. A. (1999). Synchronization, anticipation, and consistency in motor timing of children with dimensionally defined attention deficit hyperactivity behaviour. Perceptual \& Motor Skills, 89, 1237-1258. doi: 10.2466/ pms.1999.89.3f.1237 الس الس

Sagvolden, T., Johansen, E. B., Aase, H. \& Russell, V. A. (2005). A dynamic developmental theory of attention-deficit/hyperactivity disorder (ADHD) predominantly hyperactive/ impulsive and combined subtypes. Behavioral \& Brain Sciences, 28, 397-419. doi:

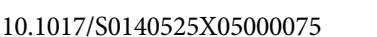

Smith, A., Cubillo, A., Barrett, N., Giampietro, V., Simmons, A., Brammer, M. \& Rubia, K. (2013). Neurofunctional effects of methylphenidate and atomoxetine in boys with attention-deficit/hyperactivity disorder during time discrimination. Biological Psychiatry, 74, 615-622. doi: 10.1016/j.biopsych.2013.03.030 الس السلسلس

Smith, A., Taylor, E., Rogers, J. W., Newman, S. \& Rubia, K. (2002). Evidence for a pure time perception deficit in children with ADHD. Journal of Child Psychology and Psychiatry, 43, 529-542. doi: 10.1111/1469-7610.00043 المالسلسلسال

Sonuga-Barke, E., Bitsakou, P. \& Thompson, M. (2010). Beyond the dual pathway model: evidence for the dissociation of timing, inhibitory, and delay-related impairments in attention-deficit/hyperactivity disorder. Journal of the American Academy of Child \& Adolescent Psychiatry, 49, 345-355. doi: 10.1016/j.jaac.2009.12.018 السلسلس

Sonuga-Barke, E., Saxton, T. \& Hall, M. (1998). The role of interval underestimation in hyperactive children's failure to suppress responses over time. Behavioural Brain Research, 94, 45-50. doi: 10.1016/S0166-4328(97)00168-X المالسلس

Steinhausen, H. (2002). Psychische Störungen bei Kindern und Jugendlichen. Lehrbuch der Kinder- und Jugendpsychiatrie [Mental disorders in children and adolescents. Textbook of child and adolescent psychiatry]. Urban \& Fischer.

Suarez, I., De Los Reyes Aragón, C., Diaz, E., Iglesias, T., Barcelo, E., Velez, J. I. \& Casini, L. (2020). How is temporal processing affected in children with attention-deficit/hyperactivity disorder? Developmental Neuropsychology, 45, 246-261. doi:

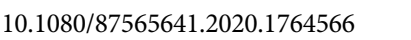

Taylor, E., Döpfner, M., Sergeant, J., Asherson, P., Banaschewski, T., Buitelaar, J., Coghill, D., Danckaerts, M., Rothenberger, A., SonugaBarke, E., Steinhausen, H. \& Zuddas, A. (2004). European clinical guidelines for hyperkinetic disorder - first upgrade. European Child \& Adolescent Psychiatry, 13, 17-130. doi: 10.1007/s00787-0041002-x

Tobia, V., Rinaldi, L. \& Marzocchi, G. M. (2018). Time processing impairments in preschoolers at risk of developing difficulties in mathematics. Developmental Science, 21, e12526. doi: 10.1111/desc.12526 السلسلس

Toplak, M. E., Dockstader, C. \& Tannock, R. (2006). Temporal information processing in ADHD: Findings to date and new methods. Journal of Neuroscience Methods, 151, 15-29. doi: 10.1016/j.jneumeth.2005.09.018 سلس

Toplak, M. E., Rucklidge, J. J., Hetherington, R., John, S. C. \& Tannock, R. (2003). Time perception deficits in attention-deficit/ hyperactivity disorder and comorbid reading diffuculties in child and adolescent samples. The Journal of Child Psychology and Psychiatry, 44, 888-903. doi: 10.1111/1469-7610.00173 المالسلس

Valko, L., Schneider, G., Doehnert, M., Müller, U., Brandeis, D., Steinhausen, H. \& Drechsler, R. (2010). Time processing in children and adults with ADHD. Journal of Neural Transmission, 117, 1213-1228. doi: 10.1007/s00702-010-0473-9

Walg, M., Hapfelmeier, G., El-Wahsch, D. \& Prior, H. (2017). The 
faster internal clock in ADHD is related to lower processing speed: WISC-IV profile analyses and time estimation tasks facilitate the distinction between real ADHD and pseudo-ADHD. European Child \& Adolescent Psychiatry, 26, 1177-1186. doi: 10.1007/s00787017-0971-5 سلس

Walg, M., Oepen, J. \& Prior, H. (2015). Adjustment of time perception in the range of seconds and milliseconds: The nature of timeprocessing alterations in children with ADHD. Journal of Attention Disorders, 19, 755-763. doi: 10.1177/1087054712454570 السلسلس الس الس

Weiß, R. (2006). Grundintelligenztest Skala 2, CFT 20-R [Culture Fair Intelligence Test II]. Hogrefe.

Wennberg, B., Janeslätt, G., Gustafsson, P. A. \& Kjellberg, A. (2021). Occupational performance goals and outcomes of time-related interventions for children with ADHD Scandinavian Journal of Occupational Therapy, 28, 158-170. doi: 10.1080/11038128.2020.1820570 المسلس

Wennberg, B., Janeslätt, G., Kjellberg, A. \& Gustafsson, P.A. (2018). Effectiveness of time-related interventions in children with ADHD aged 9-15 years: a randomized controlled study. European Child \& Adolescent Psychiatry, 27, 329-342. doi: 10.1007/s00787-017-1052-5 الملسلسلس

Wilkening, F., Levin, I. \& Druyan, S. (1987). Children's counting strategies for time quantification and integration. Developmental Psychology, 23, 823-831. doi: 10.1037/0012-1649.23.6.823 الملسلس
Willcutt, E. G. (2015). Theories of ADHD. In R. A. Barkley (Ed.), Attention-deficit hyperactivity disorder, a handbook for diagnosis and treatment, fourth edition (pp. 391-404). The Guilford Press.

Zakay, D. (1989). Subjective time and attentional resource allocation: an integrated model of time estimation. In: I. Levin \& D. Zakay (Eds.), Time and human cognition, a life-span perspective (pp. 365411). Elsevier Science Publishers.

Zakay, D. \& Block, R.A. (2004). Prospective and retrospective duration judgments: An executive-control perspective. Acta Neurobiologiae Experimentalis, 64, 319-328. Wلس الم

Zheng, Q., Wang, X., Chiu, K. Y. \& Shum, K. K. (2020). Time perception deficits in children and adolescents with ADHD: A metaanalysis. Journal of Attention Disorders. Advance online publication. doi:10.1177/1087054720978557 الهلسلسل 